\title{
Helicobacter pylori: A Cause of Community- Acquired Pediatric Septic Shock: A Cross Sectional Study
}

HebatAllah Algebaly ( $\square$ heba_elgebaly@hotmail.com )

Cairo University https://orcid.org/0000-0003-3570-0421

Rasha Elsherif

Cairo University

Doaa Ghaith

Cairo University

Bassem Saad

Cairo university

Nabil Mohsen

Cairo University

Research article

Keywords: 16s RNA, Community acquired sepsis, Helicobacter pylori, Septic shock

Posted Date: October 8th, 2019

DOI: https://doi.org/10.21203/rs.2.15769/v1

License: (c) (1) This work is licensed under a Creative Commons Attribution 4.0 International License.

Read Full License 


\section{Abstract}

Background: Blood culture negative sepsis is a diagnostic challenge to both clinicians and microbiologists. We aimed to investigate blood culture negative cases of community-acquired sepsis among children admitted at pediatric intensive care unit of Cairo University Specialized Children Hospital, Egypt.

Methodology: Our cross-sectional study was carried out over a period of six months. Electrical cardiometry was used to assess the patients' status. For blood culture negative samples, broad range bacterial and fungal PCR amplification and sequencing were performed.

Results: Among 43 patients, 9 samples were positive to pan bacterial 16srRNA gene, while five samples $(20,22,23,24,25)$ were identified as Helicobacter pylori positive with the following sequence accession numbers respectively (KT198991.1, JQ323580.1, APEL01000010.1, APEL01000010.1, CP007603.1). Patients $\mathrm{H}$ pylori positive higher $\mathrm{C}$ reactive protein, longer duration of ventilation, higher stroke volume variation and pre-ejection period $(P$ value $=0.005,0.005,0.043 \& 0.043)$

Conclusion: Detection of Helicobacter pylori in community acquired septic children alarms the necessity to conduct epidemiological studies on populations of septic shock in countries with high prevalence of $\mathrm{H}$. pylori such as Egypt.

\section{Background}

In 2017, the World Health Organization adopted a resolution on improving the prevention, recognition, and management of sepsis. Most sepsis cases and deaths are estimated to occur in low and middle-income countries. Important differences in the populations at risk, infecting pathogens, and clinical capacity to manage sepsis in high and low-resource settings necessitate context-specific approaches to this significant problem. ${ }^{[1,2]}$

The microbiologic paradigm holds that the inflammatory response of severe sepsis and septic shock cannot be overcome unless the underlying infection has been effectively eradicated. Survival depends upon the timely reduction and eradication of infection after the onset of hypotension. Empiric antimicrobial therapy must assume a position of co-primacy in the initial resuscitation with an eye toward optimizing selection, and delivery at the first dose. ${ }^{[3]}$

The difficulties in identifying the responsible pathogens are global and become exaggerated with the use of the over the counter antibiotics in some developing countries. Multicenter studies published in the last decade found that culture-negative patients accounted for $28 \%-49 \%$ of all cases of severe sepsis in North American, Spanish, French, and Canadian ICUs, respectively ${ }^{[4,5,6]}$. The figure was $40 \%$ in the panEuropean Sepsis Occurrence in Acutely III Patients (SOAP) study [7]. 
A review of 15 studies of neonatal sepsis in developing countries, performed in the late 1990s found that the most commonly encountered species in blood culture-cases were gram negative spp. These studies were hospital-based, it was likely to be nosocomial and thus not reflective of community-acquired serious bacterial infection [WHO, 1999]. ${ }^{[8]}$ Another large study of young infants aged 0-59 days demonstrated a broad array of Gram-positive and Gram-negative pathogens responsible for community-acquired bacteremia. ${ }^{[9]}$

We aimed to investigate blood culture negative cases of community-acquired septic shock among children admitted to the pediatric intensive care unit (PICU) of Cairo University Specialized Children Hospital, Cairo Egypt.

\section{Methodology}

The present study was a cross-sectional study that was carried out over a period of six months at the PICU of Cairo University Specialized Children Hospital, Egypt. The study protocol was approved by our Institutional Review Board and Ethical Committee.

We included children who fulfilled the following criteria: children aged from 1 month to 12 years with strong clinical diagnosis of septic shock at time of admission. We defined pediatric septic shock based on the American college of critical care medicine and international pediatric Society of Critical Care definitions for sepsis. ${ }^{[10]}$ We excluded patients with known congenital heart disease or cardiomyopathy, or whose duration of stay in PICU was less than 48 hours. Children with known metabolic disorders or adrenal insufficiency were also excluded.

The Electrical Cardiometery (EC, manufactured by Oskypa Medical Data) parameters were measured in the emergency department after fluid boluses. Cold septic shock was defined as cardiac index $<3.3$ $\mathrm{L} / \mathrm{min} / \mathrm{m}^{2}$ and systemic vascular resistance index $>1600$ (dyne $\mathrm{s} / \mathrm{cm}^{5} / \mathrm{m}^{2}$ ) while warm septic shock was defined as cardiac index $>5.5 \mathrm{~L} / \mathrm{min} / \mathrm{m}^{2}$ and systemic vascular resistance index $<800$ (dyne s/cm5/ $\mathrm{m}^{2}$ ). [11]

Sepsis profile was withdrawn before antibiotics administration in the hospital, including: complete blood count, C-reactive protein and blood culture (BACTEC Plus aerobic/F and BACTEC Plus anaerobic/F blood culture bottles; Becton, Dickinson and Company, Spain). Subcultures were done on blood, MacConkey's and chocolate agars incubated in $5 \% \mathrm{CO}_{2}$ at $35^{\circ} \mathrm{C}$ for 48 hours and on Sabouraud's dextrose agar incubated at $25^{\circ} \mathrm{C}$ for up to 14 days and examined every 48 hours for any growth. Further growth identification was done by Vitek 2 compact system (Biomerieux, France). Additionally, a broad-range bacterial and fungal PCR amplification for all culture negative samples was done ${ }^{[12,13]}$

Amplified DNA fragments were separated by agarose gel electrophoresis and stained with ethidium bromide and visualized under UV light, using pan bacterial 536f 5'CAGCAGCCGCGGTAATAC ${ }^{[14]}$ and the pan fungal ITS -1 5'TCCGTAGGTGAACCTGCGGG. The molecular sizes of fragments generated by 
electrophoresis were judged by comparison with the molecular weight standards as previously described [15]. An extracted DNA of $E$ coli strain was used as a positive control, whereas the negative control to detect reagent contamination was included in each PCR reaction, containing all components except the DNA extract, which was replaced by $2 \mu$ of sterile distilled $\mathrm{H}_{2} \mathrm{O}$.

\section{Sequencing analysis}

Culture negative samples were negative for ITS-1 pan fungal gene, whereas positive for pan bacterial 16srRNA gene and were subjected to sequencing. All procedures for sequencing were conducted by Macrogen (Seoul, South Korea) using ABI PRISM BigDye Terminator Cycle Sequencing Kit with AmpliTaq DNA polymerase (FS enzyme; Applied Biosystems) according to manufacturer instruction. All fluorescentlabeled fragments were purified from the unincorporated terminators with an ethanol precipitation protocol. The samples were resuspended in distilled water and subjected to electrophoresis in an $A B I$ 3730x1 sequencer (Applied Biosystem, USA). Nucleotide sequence similarities were determined using other known sequences found in the GenBank database using BLAST program of National Center for Biotechnology Information (NCBI) databases (http://www.ncbi.nlm.nih.gov/blast).

Statistical Analysis:

An Excel spreadsheet was established for the entry of data. We used validation checks on numerical variables and option-based data entry method for categorical variables to reduce potential errors. The analyses were carried with SPSS software (Statistical Package for the Social Sciences, version 24, SSPS Inc, Chicago, IL, USA). Frequency tables with percentages were used for categorical variables and descriptive statistics (median and interquartile range [IQR]) were used for numerical variables. Independent Student t-test, paired t-test, or Mann-Whitney tests were used to compare quantitative variables, while Chi-square test or McNemar-Bowker tests were used to analyze categorical variables. A pvalue $<0.05$ is considered statistically significant.

\section{Results}

Difference in baseline characters: Among 400 admissions in PICU of Cairo University Specialized Children Hospital over a 6-month period from March 2017 to September 2017, 43 patients were diagnosed as septic shock; cold septic shock constituted $53 \%(n=23) ; 62 \%$ were males, with a median weight of $8 \mathrm{~kg}$. Gastroenteritis was the most common septic focus. Only seven patients had positive blood culture on admission. There was no statistically significant difference between warm and cold septic shock patients in terms of age $(p=0.102)$, gender $(p=0.091)$, weight $(p=0.125)$, diagnosis $(p=0.12)$, need for ventilation $(p=0.32)$, duration of hospital stay $(p=0.975)$, Pediatric Index of Mortality2 (PIM2) score $(p=$ $0.212)$, blood culture $(p=0.309)$, or PCR results $(p=0.67)$ (Table 1$)$.

Regarding the EC parameters after fluid boluses, apart from the known hemodynamic difference between warm and cold shock in cardiac index and systemic vascular resistance index, the median index of 
contractility (ICON) was significantly higher among patients with warm septic shock than patients with cold septic shock $(p=0.008)$. The thoracic fluid content $(T F C)$, diffusion of oxygen $\left(\mathrm{DO}_{2}\right)$ and stroke volume (SV) were significantly higher in warm septic shock ( $p=0.007,0.003$ and $<0.001$, respectively) (Table 2).

Microbiology results: Out of 43 septic shock cases, 7 blood culture samples were positive (3 Escherichia coli, 2 Staph. epidermidis, 1 Pseudomonas aeruginosa, 1 Candida tropicalis).. 28 culture negative samples were negative for ITS- 1 pan fungal gene, whereas 9 samples were positive to pan bacterial 16srRNA gene. By sequencing, 5 samples (20, 22, 23, 24 and 25) were identified as Helicobacter pylori with the following sequence accession numbers respectively (KT198991.1, JQ323580.1, APEL01000010.1, APEL01000010.1, CP007603.1). while, the rest of the 9 samples hit negative in the sequencing.

In all five positive for $\mathrm{H}$ pylori, we could observe a higher CRP, longer duration of ventilation, higher stroke volume variation and pre-ejection period $(P$ value $=0.005,0.005,0.043 \& 0.043)$ in patients with $\mathrm{H}$ pylori positive septic shock $H$. pylori cases and the rest of the no growth group (Table 3 )

\section{Discussion}

Sepsis is the primary cause of death from infection, especially if not recognized and treated promptly. Its recognition mandates urgent attention. ${ }^{[16]}$ Delayed antimicrobial therapy was an independent risk factor for mortality and prolonged organ dysfunction in pediatric sepsis. ${ }^{[17]}$ SPROUT study included 6925 children from 26 countries; 500 were diagnosed as severe sepsis. The etiology was gram negative in 158 patients and gram positive in 150. ${ }^{[18]}$

H. pylori DNA was identified from 5 of our community acquired septic shock patients with negative blood cultures. However, in Egyptian school children, H pylori infection prevalence was $73 \%$ in 2008. ${ }^{[19]}$ The prevalence of $H$. pylori is not evenly distributed worldwide. It depends on socio-economic status and overcrowding. H. pylori, which is transmitted by the oral-oral or fecal-oral route, is rampant in low middle income countries owing to overcrowding and poor sanitation and hygiene. ${ }^{[20]}$ There are some reports about the link of $H$. pylori to extragastric disease. In their latest guidelines, ESPGHAN/NASPGHAN provided one weak recommendation for testing and treating $H$. pylori infection in the patient with idiopathic thrombocytopenic purpura. ${ }^{[21]}$ H. pylori is linked in recent review to adult cardiovascular, neurologic, dermatologic, obstetric, immunologic, and metabolic diseases. ${ }^{[22]}$ Increase in serum levels of IL1 $\beta$ and TNF-a cytokines were reported in serum of people infected with H. pylori. ${ }^{[23]}$ Previous reports described a significant increase in oxidative stress in the blood of infected adults. ${ }^{24-25]}$

Numerous factors are known to control the translocation of the microbe across the gastrointestinal barrier. H. pylori may influence the ecology of gastrointestinal microflora causing disturbance of intestinal mucosal barrier. These effects may contribute to invasion of the bloodstream by the bacterium. ${ }^{\text {[26] }}$ Sepsis syndrome by H. pylori was mentioned in the literature in case report with respiratory failure as the 
initial presentation. ${ }^{[27]} \mathrm{H}$. fennelliae was previously described to cause sepsis in a child with leukemia and adult with HIV [28-29]

Conclusion: Detection of Helicobacter pylori in the blood of 5 children alerts the need to conduct epidemiological studies on populations of septic shock in countries with high prevalence of $H$. pylori.

\section{Declarations}

- The study protocol was approved by our Institutional Review Board and Ethical Committee. Prof. Ayman Saed Salem. Faculty of medicine,Cairo University.

- Written consent from the caregiver was obtained

- Availability of data and materials: The datasets used and/or analyzed during the current study are available from the corresponding author on reasonable request.

- There is no competing interests

- The study received no Funding

- Authors' contributions: HF was the author of the idea, study design, results and major contributor to the manuscript, NM revised the process, BS collected the data, RE analyzed the PCR data, DG analyzed the sequence data. All authors have read and approved the manuscript.

- Acknowledgements: we would like to thank professor Hanaa El karaksy for final editing of the manuscript.

\section{Abbreviations}

$\mathrm{Cl}$ : cardiac index, $\mathrm{CPI}$ : cardiac performance index, $\mathrm{DO}_{2}$ : oxygen delivery, $\mathrm{HR}$ : heart rate, ICON: index of contractility, PCR: polymerase chain reaction, SV: stroke volume, SVRI: systemic vascular resistance index, TFC: thoracic fluid content. CONS: coagulase-negative Staphylococci, E. coli: Escherichia coli, PCR: Polymerase chain reaction, PIM2: Pediatrc index of mortality2. PEP: prejection period, SV: stroke volume, SVV: stroke volume variation,

\section{References}

1. Rudd KE, Kissoon N, Limmathurotsakul D, Bory S, Mutahunga B, Seymour CW, Angus DC, West TE. The global burden of sepsis: barriers and potential solutions. Crit Care. 2018;22:232.

2.Reinhart K, Daniels R, Kissoon N, Machado FR, Schachter RD, Finfer S. Recognizing sepsis as a global health priority - a WHO resolution. N Engl J Med 2017;377:414-7.

3.Liang SY, Kumar A. Empiric antimicrobial therapy in severe sepsis and septic shock: optimizing pathogen clearance. Curr Infect Dis Rep 2015;17: 493. 
4. Kumar A, Roberts D, Wood KE, Light B, Parrillo JE, Sharma S, Suppes R, Feinstein D, Zanotti S, Taiberg L, Gurka D, Kumar A, Cheang M: Duration of hypotension before initiation of effective antimicrobial therapy is the critical determinant of survival in human septic shock. Crit Care Med 2006; 34:1589-1596.

5. Blanco J, Muriel-Bombin A, Sagredo V, Taboada F, Gandia F, Tamayo L, Collado J, Garcia-Labattut A, Carriedo D, Valledor M, De Frutos M, Lopez MJ, Caballero A, Guerra J, Alvarez B, Mayo A, Villar J: Incidence, organ dysfunction and mortality in severe sepsis: a Spanish multicentre study. Crit Care 2008; 12:R158.

6. Martin CM, Priestap F, Fisher H, Fowler RA, Heyland DK, Keenan SP, Longo CJ, Morrison T, Bentley D, Antman N: A prospective, observational registry of patients with severe sepsis: the Canadian Sepsis Treatment and Response Registry. Crit Care Med 2009; 37:81-88.

7. Vincent JL, Sakr Y, Sprung CL, Ranieri VM, Reinhart K, Gerlach H, Moreno R, Carlet J, Le Gall JR, Payen D: Sepsis in European intensive care units: results of the SOAP study. Crit Care Med 2006; 34:344-353.

8. World Health Organization Young Infants Study Group. Serious infections in young infants in developing countries: rationale for a multicenter study. Pediatr Infect Dis J 1999;10: S4-S7.

9. Hamer DH, Darmstadt GL, Carlin JB, Zaidi AK, Yeboah-Antwi K, Saha SK, Ray P, Narang A, Mazzi E, Kumar P, Kapil A, Jeena PM, Deorari A, Chowdury AK, Bartos A, Bhutta ZA, Adu-Sarkodie Y, Adhikari M, Addo-Yobo E, Weber MW; Young Infants Clinical Signs Study Group. Etiology of bacteremia in young infants in six countries. Pediatr Infect Dis J. 2015;34 (1):e1-e8.

10. Goldstein B, Giroir B, Randolph A. International pediatric sepsis consensus conference: Definitions for sepsis and organ dysfunction in pediatrics. Pediatr. Crit. Care Med 2005; 62-8.

11. Brierley J, Carcillo JA, Choong K, Cornell T, Decaen A, Deymann A, Doctor A, Davis A, Duff J, Dugas MA, Duncan A, Evans B, Feldman J, Felmet K, Fisher G, Frankel L, Jeffries H, Greenwald B, Gutierrez J, Hall M, Han YY, Hanson J, Hazelzet J, Hernan L, Kiff J, Kissoon N, Kon A, Irazuzta J, Lin J, Lorts A, Mariscalco M, Mehta R, Nadel S, Nguyen T, Nicholson C, Peters M, Okhuysen-Cawley R, Poulton T, Relves M, Rodriguez A, Rozenfeld R, Schnitzler E, Shanley T, Kache S, Skippen P, Torres A, von Dessauer B, Weingarten J, Yeh T, Zaritsky A, Stojadinovic B, Zimmerman J, Zuckerberg A. Clinical practice parameters for hemodynamic support of pediatric and neonatal septic shock: 2007 update from the American College of Critical Care Medicine. Crit Care Med.2009;37:666-88.

12.Goldenberger, D., I. Perschil, M. Ritzler, and M. Altwegg. A simple "universal" DNA extraction procedure using SDS and proteinase K is compatible with direct PCR amplification. PCR Methods Applic 1995; 4:368-370.

13.Goldenberger, D., T. Schmidheini, and M. Altwegg. Detection of Bartonella henselae and B. quintana by a simple and rapid procedure using broad-range PCR amplification and direct single-strand sequencing of a part of the 16S rRNA gene. Clin Microbiol Infect 1997; 3:240-245. 
14.Bousbia S, Papazian L, Auffray JP, Fenollar F, Martin C, Li W, Chiche L, La Scola B, Raoult D. Tropheryma whipplei in patients with pneumonia. Emerg Infect Dis. 2010; 16:258-63.

15.Henry TP, Iwen C, Hinrichs SH. Identification of Aspergillus species using internal transcribed spacer regions 1 and 2. J Clin Microbiol 2000; 38:1510-5.

16. Singer M, Deutschman CS, Seymour CW, Shankar-Hari M, Annane D, Bauer M, Bellomo R, Bernard GR, Chiche JD, Coopersmith CM, Hotchkiss RS, Levy MM, Marshall JC, Martin GS, Opal SM, Rubenfeld GD, van der Poll T, Vincent JL, Angus DC. The Third International Consensus Definitions for Sepsis and Septic Shock (Sepsis-3). JAMA.2016 23;315: 801-10.

17.Weiss SL, Fitzgerald JC, Balamuth F, Alpern ER, Lavelle J, Chilutti M, Grundmeier R, Nadkarni VM, Thomas NJ. Delayed antimicrobial therapy increases mortality and organ dysfunction duration in pediatric sepsis. Crit Care Med. 2014;42:2409-2417.

18. Weiss SL, Fitzgerald JC, Pappachan J, Wheeler D, Jaramillo-Bustamante JC, Salloo A, Singhi SC, Erickson S, Roy JA, Bush JL, Nadkarni VM, Thomas NJ; Sepsis Prevalence, Outcomes, and Therapies (SPROUT) Study Investigators and Pediatric Acute Lung Injury and Sepsis Investigators (PALISI) Network. Global epidemiology of pediatric severe sepsis: the sepsis prevalence, outcomes, and therapies study. Am J Respir Crit Care Med 2015;191:1147-1157.

19. Mohammad MA, Hussein L, Coward A, Jackson SJ. Prevalence of Helicobacter pylori infection among Egyptian children: impact of social background and effect on growth. Public Health Nutr. 2008;11:230-6

20. Poddar U. Helicobacter pylori: a perspective in low- and middle-income countries. Paediatr Int Child Health.2019;39:13-17.

21. Jones NL, Koletzko S, Goodman K, Bontems P, Cadranel S, Casswall T, Czinn S, Gold BD, Guarner J, Elitsur Y, Homan M, Kalach N, Kori M, Madrazo A, Megraud F, Papadopoulou A, Rowland M; ESPGHAN, NASPGHAN. Joint ESPGHAN/ NASPGHAN guidelines for the management of Helicobacter pylori in children and adolescents (Update 2016). J Pediatr Gastroenterol Nutr. 2017;64:991-1003

22. Ražuka-Ebela, D, Giupponi, B, Franceschi, F. Helicobacter pylori and extragastric diseases. Helicobacter 2018; 23(1):e12520

23..Moradipour A, Khosravi A, Piri F. Fecal Helicobacter pylori glmM and 16S rRNA genes correlate with serum TNF-a and IL-1 $\beta$ cytokine fluctuations. Acta Microbiol Immunol Hung. 2018;65:489-499.

24.Khanzode SS, Khanzode SD and Dakhale GN. Serum and plasma concentration of oxidant and antioxidants in patients of Helicobacter pylori gastritis and its correlation with gastric cancer. Cancer Lett $2003 ; 95,27-31$.

25. Siomek A, Rytarowska A, Szaflarska-Poplawska A, Gackowski D, Rozalski R, Dziaman T, CzerwionkaSzaflarska M, Olinski R. Helicobacter pylori infection is associated with oxidatively damaged DNA in 
human leukocytes and decreased level of urinary 8-0xo-7,8-dihydroguanine. Carcinogenesis 2006; 27:405-8.

26. De Luca C, Mancin A, Calabrò M, Daleno C, Ferrario A, Renzulli R, Scuderi C, Casari E. Helicobacter pyloribacteremia: An Unusual Finding. Infect Dis Rep 2016; 3;8:6612..

27. Ndawula EM, Owen RJ, Mihr G, Borman P, Hurtado A. Helicobacter pylori bacteraemia. Clin. Microbiol Infect.Dis 1994; 13(7):621

28. Orlicek SL, Welch DF, Kuhls TL. Helicobacter fennelliae bacteremia in a child with leukemia. Infect Dis Clin Pract 1994; 3: 450- 1.

29. Hsueh PR, Teng LJ, Hung CC, Chen YC, Yang PC, Ho SW, Luh KT. Septic shock due to Helicobacter fennelliae in non-human immunodeficiency virus-infected heterosexual patient. J Clin Microbiol 1999; 37: 2084- 6.

\section{Tables}

\section{Table 1: Characteristics of the study population}




\begin{tabular}{|c|c|c|}
\hline \multirow[t]{2}{*}{ Variables } & \multicolumn{2}{|c|}{ Patients $(\mathrm{N}=43)$} \\
\hline & No & $\%$ \\
\hline Age in Months; Median (IQR) & \multicolumn{2}{|c|}{$10(6-48)$} \\
\hline Male & 27 & 62.7 \\
\hline Female & 16 & 37.3 \\
\hline Weight in Kg; Median (IQR) & \multicolumn{2}{|c|}{$8.3(6-14.2)$} \\
\hline \multicolumn{3}{|l|}{ Septic focus } \\
\hline Gastroenteritis & 18 & 41.9 \\
\hline Pneumonia & 12 & 27.9 \\
\hline Meningitis & 11 & 25.6 \\
\hline Bloodstream infection & 1 & 2.3 \\
\hline \multicolumn{3}{|l|}{ Blood Culture results } \\
\hline Candida & 1 & 2.3 \\
\hline CONS* & 2 & 4.7 \\
\hline E. coli* & 3 & 5.9 \\
\hline No growth & 36 & 81.4 \\
\hline Pseudomonas & 1 & 2.3 \\
\hline \multicolumn{3}{|l|}{ PCR results } \\
\hline PCR Positive* & 9 & 25 \\
\hline PCR Negative & 27 & 75 \\
\hline \multicolumn{3}{|c|}{ Duration of hospital stay in days; } \\
\hline Median (IQR) & \multicolumn{2}{|c|}{$11.5(8-26.2)$} \\
\hline Ventilation & $\mathrm{N}=40$ & $93 \%$ \\
\hline \multicolumn{3}{|c|}{ Duration of ventilation in days; Median (IQR) } \\
\hline & \multicolumn{2}{|c|}{$10.5(6.8-20)$} \\
\hline PIM2 score* Mean (SD) & \multicolumn{2}{|c|}{$75.91(5.3)$} \\
\hline \multicolumn{3}{|l|}{ Type of septic shock } \\
\hline Warm & 20 & 46.5 \\
\hline Cold & 23 & 53.5 \\
\hline
\end{tabular}

CONS: coagulase-negative Staphylococci, E. coli: Escherichia coli, PCR: Polymerase chain reaction, PIM2: Pediatrc index of mortality2

Table 2: Difference in clinical parameters between patients with warm and cold septic shock on admission to the emergency room 


\begin{tabular}{|c|c|c|c|c|c|}
\hline Variables & \multicolumn{2}{|c|}{ Warm shock $(\mathrm{N}=20)$} & \multicolumn{2}{|c|}{ Cold Shock $(\mathrm{N}=23)$} & P-value \\
\hline Age in months; & \multirow{2}{*}{\multicolumn{2}{|c|}{$17(7.5-66)$}} & \multirow{2}{*}{\multicolumn{2}{|c|}{$8(4-30)$}} & \\
\hline Median (IQR) & & & & & 0.102 \\
\hline Male & 10 & 50.0 & 17 & 73.9 & \\
\hline Female & 10 & 50.0 & 6 & 36.1 & 0.091 \\
\hline Weight in kg; Median (IQR) & \multicolumn{2}{|c|}{$9(7.5-15)$} & \multicolumn{2}{|c|}{$8(5.5-13)$} & 0.125 \\
\hline \multicolumn{6}{|l|}{ Septic focus } \\
\hline Bloodstream; N (\%) & \multicolumn{2}{|c|}{$1(5)$} & \multicolumn{2}{|c|}{$0(0)$} & \multirow[t]{4}{*}{0.123} \\
\hline Gastroenteritis; N (\%) & \multicolumn{2}{|c|}{$6(30)$} & \multicolumn{2}{|c|}{$12(52.2)$} & \\
\hline Meningitis; N (\%) & \multicolumn{2}{|c|}{$8(40)$} & \multicolumn{2}{|c|}{$3(13.3)$} & \\
\hline Pneumonia; N (\%) & \multicolumn{2}{|c|}{$5(25)$} & \multicolumn{2}{|c|}{$7(30.5)$} & \\
\hline \multicolumn{6}{|l|}{ Blood Culture results } \\
\hline PCR Positive* & \multicolumn{2}{|c|}{$5(25)$} & \multicolumn{2}{|c|}{$9(39.1)$} & \multirow[t]{2}{*}{0.67} \\
\hline PCR Negative & \multicolumn{2}{|c|}{$15(75)$} & \multicolumn{2}{|c|}{$14(60.9)$} & \\
\hline CI, median (IQR) & \multicolumn{2}{|c|}{$6(5.9-6.4)$} & \multicolumn{2}{|c|}{$2.8(2.5-3.1)$} & $<0.001$ \\
\hline ICON, median (IQR) & \multicolumn{2}{|c|}{$106(82.5-133.5)$} & \multicolumn{2}{|c|}{$68(50-93)$} & 0.008 \\
\hline SVRI, median (IQR) & \multicolumn{2}{|c|}{790 (763 - 903) } & \multicolumn{2}{|c|}{$1921(1700-2203.5)$} & $<0.001$ \\
\hline TFC, median (IQR) & \multicolumn{2}{|c|}{$282.5(247-320)$} & \multicolumn{2}{|c|}{$232(198-265)$} & 0.007 \\
\hline $\mathrm{DO}_{2}$, median (IQR) & \multicolumn{2}{|c|}{$340.5(255.5-421.5)$} & \multicolumn{2}{|c|}{$249(144-301)$} & 0.003 \\
\hline CPI, median (IQR) & \multicolumn{2}{|c|}{$0.74(0.61-1.19)$} & \multicolumn{2}{|c|}{$0.5(0.44-0.71)$} & 0.002 \\
\hline HR, median (IQR) & \multicolumn{2}{|c|}{$149(134-159)$} & 139.2 & $1.5-161)$ & 0.214 \\
\hline SV, median (IQR) & 23 & 32.25) & & $-11)$ & $<0.001$ \\
\hline
\end{tabular}

CI: cardiac index, $\mathrm{CPI}$ : cardiac performance index, $\mathrm{DO}_{2}$ : oxygen delivery, HR: heart rate, ICON: index of contractility, PCR: polymerase chain reaction, SV: stroke volume, SVRI: systemic vascular resistance index, TFC: thoracic fluid content.

Table 3: Difference in clinical and EC parameters on admission between patients with $H$. pylori positive and $H$. pylori negative septic shock 


\begin{tabular}{|c|c|c|c|}
\hline Variables (median \&IQ) & H. pylori negative $(\mathrm{n}=23)$ & $\begin{array}{c}\text { H. pylori positive } \\
(\mathrm{n}=5)\end{array}$ & P value \\
\hline Age & $10(5: 72)$ & $24(9: 30)$ & 0.664 \\
\hline Weight & $8(6: 15)$ & $10(8.5: 13)$ & 0.453 \\
\hline Duration of MV & $9(7: 15)$ & $24(20: 35)$ & 0.005 \\
\hline Duration of stay & $11(8: 18)$ & $24(20: 38)$ & 0.183 \\
\hline CRP & $91(48: 96)$ & $190(96: 220)$ & 0.005 \\
\hline PIM 2 Score & $75.5(71: 80)$ & $80(75: 81)$ & 0.155 \\
\hline $\mathrm{CI}$ & $5.6(2.8: 6)$ & $6.3(3.1: 7)$ & 0.155 \\
\hline TFC & $43.5(28: 53)$ & $45(33: 46)$ & 0.6 \\
\hline ICON & $92(68: 107)$ & $80(70: 109)$ & 0.94 \\
\hline SVV & $16(13: 18)$ & $9(9: 14)$ & 0.043 \\
\hline SVRI & 1079(795:1921) & $920(780: 1700)$ & 0.567 \\
\hline PEP & $77.5(67: 93)$ & $100(86: 115)$ & 0.043 \\
\hline DO2 & $277.5(155: 388)$ & $302(251: 322)$ & 0.567 \\
\hline CPI & $0.6(0.5: 0.8)$ & $0.5(0.5: 1.2)$ & 0.945 \\
\hline HR & 154.5(137:163) & 151(149:155) & 0.631 \\
\hline Suspected initial diagnosis & $\mathrm{N}(\%)$ & $\mathrm{N}(\%)$ & \multirow{5}{*}{0.367} \\
\hline Encephalitis & $2(6.7)$ & $0(0)$ & \\
\hline Gastroenteritis & $13(40)$ & $1(20)$ & \\
\hline Meningitis & $5(16.7)$ & $3(60)$ & \\
\hline Pneumonia & $10(33.3)$ & $1(20)$ & \\
\hline
\end{tabular}

CI: cardiac index, CPI: cardiac performance index, $\mathrm{DO}_{2}$ : oxygen delivery, HR: heart rate, ICON: index of contractility, PCR: polymerase chain reaction, PEP: prejection period, SV: stroke volume, SVV: stroke volume variation, SVRI: systemic vascular resistance index, TFC: thoracic fluid content 